\title{
Silicon-Doped Nanotube (Si-CNT) as Drug Delivery Nanocarrier for Osteoporosis Drug: Quantum Chemical Study
}

Zaid Al-Sawaff ( $\sim$ zaidalsawaff@ntu.edu.iq)

NTU: Northern Technical University https://orcid.org/0000-0001-8789-4905

Fatma Kandemirli

Kastamonu University: Kastamonu Universitesi

Serap Senturk Dalgic

Trakya University: Trakya Universitesi

\section{Research Article}

Keywords: BMSF-BENZ, Drug adsorption, Si-CNT nanotube, Drug delivery system, Density functional theory, Thermodynamic properties

Posted Date: October 12th, 2021

DOI: https://doi.org/10.21203/rs.3.rs-965575/v1

License: (c) (i) This work is licensed under a Creative Commons Attribution 4.0 International License. Read Full License 


\title{
Silicon-Doped Nanotube (Si-CNT) as Drug Delivery Nanocarrier for Osteoporosis Drug: Quantum Chemical Study
}

\author{
Zaid H. Al-Sawaff ${ }^{(1)(2)}$, Fatma Kandemirli( ${ }^{(3)}$ Serap Senturk Dalgic ${ }^{(4)}$ \\ (1) Material Science \& Engineering Dept., Faculty of Engineering and Architecture, Kastamonu University, Turkey, \\ (2) Medical Instrumentation Technology, Technical Engineering College, Northern Technical University, Mosul, Iraq \\ (3) Biomedical Engineering Department, Faculty of Engineering \& Architecture, Kastamonu University, Kastamonu, \\ Turkey \\ (4) Department of Physics, Faculty of Science, Trakya University, 22030, Edirne, Turkey
}

\begin{abstract}
The aim of this study is to investigate the potential and capability of Si-CNT to detect and adsorb BMSF-BENZ ((4-bromo-7-methoxy-1-(2-methoxyethyl)-5-\{[3-(methylsulfonyl)phenyl]methyl $\}$ 2-[4-(propane-2-))yl) phenyl]-1H-1,3-benzothiazole) molecular. For this purpose, we considered different configurations for adsorbing BMSF-BENZ drug on the surface of the Si-CNT nanocluster. All considered configurations are optimized using DFT theory at the $6-31 \mathrm{G}^{* *}$ basis set and B3LYP level of theory, and then from optimized structures, for each nanoparticle, we selected four stable models for the adsorption of BMSF-BENZ from $\left(\mathrm{Br}, \mathrm{N}_{8}, \mathrm{~N}_{9}, \mathrm{~N}_{58}, \mathrm{O}_{35}, \mathrm{O}_{41}\right.$ and S) active sites on the surface the selected nanoparticle. and Quantum theory of atoms in Molecular Analysis (QTAIM), and Molecular Orbital Analysis (MO) was also established.

The calculated results indicate that the distance between nanocluster and drug from the $\mathrm{N}_{8}$ site is lower than from all other locations sites for all investigated nanoparticles, and adsorption of BMSF-BENZ from the $\mathrm{N}_{8}$ site is more favorable especially for the Si-CNT nanotube.

The adsorption energy, hardness, softness, and fermi energy results reveal that the interaction of BMSF-BENZ with Si-CNT, is an encouraging adsorbent for this drug as Eads of BMSF-BENZ/SiCNT complexes are $(-5.15,-24.21,-8.22,-17.03,-13.16,-2.22,-12.70) \mathrm{kcal} / \mathrm{mol}$ in the gas phase. As well, the appropriate and spontaneous interaction between the BMSF-BENZ drug and Si-CNT nanoparticle was confirmed by investigating the quantum chemical molecular descriptors and solvation Gibbs free energies of all atoms.

Si-CNT can be used as an amperometric sensor to detect the BMSF-BENZ drug molecule. Thus, we propose that the Si-CNT can be a promising candidate as a drug delivery vehicle for BMSFBENZ drug molecules.
\end{abstract}




\section{Keywords}

BMSF-BENZ; Drug adsorption; Si-CNT nanotube; Drug delivery system; Density functional theory; Thermodynamic properties;

\section{Introduction}

Osteoporosis is related to a decrease in bone mass and damage to the microstructure of bone tissue, which leads to an increased risk of bone fractures as a result. [1]

Several recent studies [2] have shown that one in every three women and every 12 men will suffer an osteoporotic fracture at some point in their lives. Also, 50,000 forearm fractures, 40,000 symptomatic spinal fractures, and 60,000 hip fractures have been identified to occur in the UK every year[3].

Therefore, it has become necessary to develop new strategies to treat or prevent osteoporosis in men and women, such as the discovery of a drug that enhances the determination of CaSR antagonists, that is, it is rapidly absorbed (short $\mathrm{T}_{\max }$ ) and is eliminated fairly quickly in addition to enhancing the patient's bone mass or improving the way and delivery time of the drug to the patient, ensuring that the drug is delivered safely to the intended target[4].

Based on its appropriate and practically validated chemical and physical properties[4], one of the BMSF-BENZ derivatives used in the treatment of osteoporosis was selected in our article.

The most important properties of this compound with the chemical structure (4-bromo-7-methoxy1-(2-methoxyethyl)-5-\{[3-(methylsulfonyl)phenyl]methyl $\}-2-[4-($ propane-2-))yl) phenyl]-1H1,3-benzothiazole) (Figure1) is its ability to exhibit peak releasing hormone (PTH) and novel properties with respect to the CaSR receptor[4].

With the growing development of nanoscience, the facts of nanostructures like nanosheets, nano components, nanotubes, and nanocells were extensively studied as possible candidates in many different fields [5-9]. Whereas, nanotubes are best suited as drug carriers because of their high sensitivity to drug molecules, low side effects, unique surface properties, atomic structures, etc. [10-12]. 


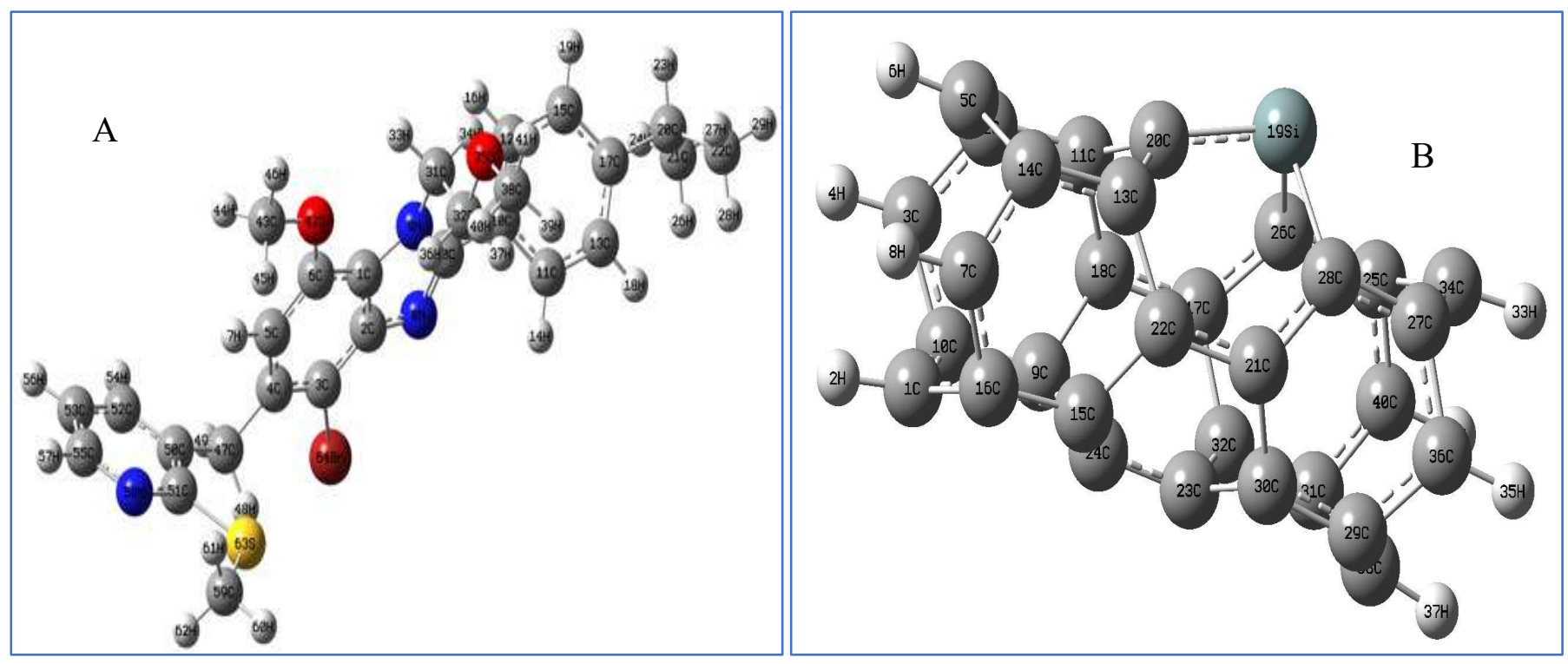

Fig.1 Optimized chemical structure of: A((4-bromo-7-methoxy-1-(2-methoxyethyl)-5-\{[3-(methylsulfonyl)phenyl]methyl $\}-2-[4-$ (propane-2-))yl) phenyl]-1H-1,3-benzothiazole), and B(Si-CNT(4,0)SWCNT)

Due to the wide scope of use of silicon-saturated carbon nanotubes in many fields, there have been many literature studies and scientific articles involving the use of this type of nanotube especially in relation to drug delivery system, so we will provide some literature reviews in the next paragraph.

\subsection{Literature reviews}

in 2012 Sazan M. Haidary et al. introduced a review on Nanoporous Silicon as Drug Delivery Systems for Cancer Therapies, and they showed that Porous silicon nanoparticles (pSi ) had been established as excellent candidates for medical applications as drug delivery devices due to their excellent biocompatibility, biodegradability, and high surface area[13]

Moreover, in 2013, PA Gowri Sankar and Udhayakumar Kaithamalai conducted a comparative (DFT) study on the electronic properties of the zigzag boron silicon $(10,0)$ single-walled carbon nanotubes, on gas molecular adsorption using nine dominant gas molecules $\left(\mathrm{H}_{2}, \mathrm{H}_{2} \mathrm{O}, \mathrm{O}_{2}, \mathrm{CO}\right.$, $\mathrm{CO}_{2}, \mathrm{NO}, \mathrm{NO}_{2}, \mathrm{NH}_{3}$, and $\mathrm{CH}_{3} \mathrm{OH}$ ) to exploit their potential applications as gas sensors.

They found that all molecules are weakly adsorbed on the original carbon nanotube adsorbent with small binding energy, while they can be either charge donors or acceptors of the nanotubes. Also, they showed that the adsorbents B-CNT and Si-CNT are highly chemicals when they were exposed to $\mathrm{NO}, \mathrm{NO}_{2}, \mathrm{O}_{2}$, and $\mathrm{CH}_{3} \mathrm{OH}$. 
The Si-CNT adsorbent adsorbs $\mathrm{H}_{2}, \mathrm{H}_{2} \mathrm{O}, \mathrm{CO}, \mathrm{CO}_{2}$, and $\mathrm{NH}_{3}$ gas molecules moderately with binding strength compared to the B-CNT adsorbent.

F.J. Martínez-Vázquez et al. published an article in 2013 dealing with the fabrication of novel Sidoped Hydroxyapatite/Gelatine scaffolds at room temperature by fast prototyping for drug delivery system and bone regeneration, and they Proved that the scaffold behaves as a hydrogel palliative the fitting to the bone defect at the time of surgery. These scaffolds show a sufficient macropore design for vascularization and a microporosity that enables fluid exchange, and the compressive conduct of such scaffolds is similar to that of trabecular bone of the same density.

Moreover, In vitro cellular investigations acquired in the well-established osteoblastic cell line $\mathrm{MC}_{3} \mathrm{~T}_{3}-\mathrm{E}_{1}$ exposed various benefits of gelatin inclusion in the material regarding cell differentiation and gene expression. Finally, the investigation indicated that these composite scaffolds are sufficient to be considered as matrices for bone regeneration and drug delivery[15]. In 2018, Rayeheh Bagheri et al. introduced a DFT study about Si-doped phagraphene as a drug carrier for adrucil anti-cancer drugs. Based on the results, a drucil drug very weakly interacts with phagraphene. However, after replacing one carbon atom with different atoms like $\mathrm{Al}, \mathrm{Si}$, and $\mathrm{B}$, the results showed that the new complex of drug/Si-CNT is more appropriate for adrucil delivery because of moderate adsorption energy, short recovery time, and the electronically harmless adsorption property [16].

The binding energy values of the Si-CNT suggest that doping of nanotube enhances the interaction mechanism and alters the structural, chemical, and electronic properties of the complexes. When the Si-doped atom interacts with the active atoms of the BMSF-BENZ (Figure 2), the new complexes become more stable, leading the binding energies to lie in the range of chemisorption [17].

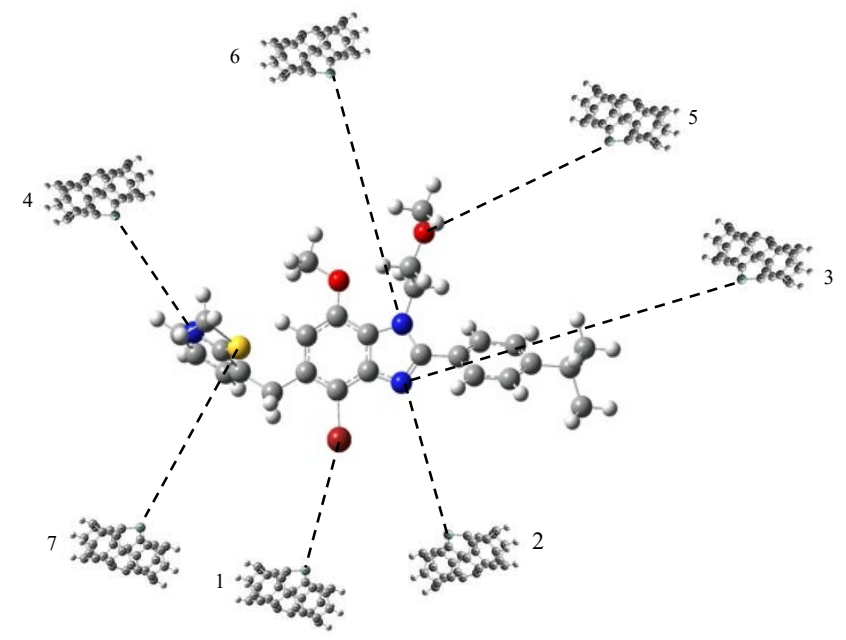

Fig.2. location of the active atoms of BMSF-BENZ where Si-doped CNT was interacting: (1) Bromine atom, (2) Nitrogen N8 atom, (3) Nitrogen $\mathrm{N}_{9}$ atom, (4) Nitrogen $\mathrm{N}_{58}$ atom, (5) Oxygen $\mathrm{O}_{35}$ atom, (6) Oxygen $\mathrm{O}_{41}$ atom, and (7) Sulfur $\mathrm{S}$ atom. 
To the authors' knowledge, no comparative investigation of BMSF-BENZ adsorption on Si$\mathrm{CNT}(4,0)$ has been previously performed. The main objective of this article is to explore the adsorption behavior of BMSF-BENZ on the zigzag surface of Si-CNT(4,0)SWCNT. For this purpose, we have a comparative investigation of various structural and electronic properties before and after adsorption of BMSF-BENZ onto the nanotube.

\section{Computational methods}

All calculations were carried out by using Density Functional Theory (DFT) with B3LYP and 6$31 \mathrm{G}^{* *}$ basis set as employed in Gaussian 09 package [18]. In this work, the vibrational frequencies for all new complexes with the original compounds were analyzed and investigated to check the true global minima of our predicted Si-CNT Nanotubes. Adsorption energy, change in energy gap, charge transfer analysis, dipole moment, and recovery time were also examined to predict the interaction between the drug molecule with nanoparticles.

In order to obtain electrical properties of complexes, the energies of Еномо and ELumo correspond to the highest occupied molecular orbital (HOMO) and the lowest occupied molecular orbital (LUMO) level, respectively were computed. Also some physico chemical parameters based on Eномо and Elumo energies, such as, electronegativity $(\chi)$, Fermi energy level (Ef), energy gap (Eg) can be calculated by the following equations : [19-21]

$\chi=-\frac{1}{2}\left(E_{\text {HOMO }}+E_{\text {LUMO }}\right)$

$E_{f}=E_{\mathrm{HOMO}}+\left(\frac{E_{L U M O}-E_{H O M O}}{2}\right)=-\chi$

$E_{g}=E_{\mathrm{LUMO}}-E_{\mathrm{HOMO}}$

Several calculations were executed to calculate the total energies of the molecules depending on the position of the nanotube attached to the drug molecule. The adsorption energies of drug on the surfaces of the nanotubes were obtained by: [22]

$E_{\text {ads }}=E_{\text {complex }}-\left(E_{\text {nanotube }}+E_{\text {drug }}\right)$

where $E_{\text {complex, }}$ Enanotube and Edrug donate the energy of the complex composed with nanotubes-drug and isolated energies of nanotube and drug, respectively. The Eads energy was determined from the summation of the interaction energy $\left(E_{\text {int }}\right)$ and deformation energies $\left(E_{\text {def }}\right)$ of the drug ( $\left.E_{\text {def- drug }}\right)$ and nanotubes (E def- nanotube $)$ during the adsorption process. [23]

$E_{\text {int }}=E_{\text {complex }}-\left(E_{\text {nanotube in complex }}+E_{\text {drug in complex }}\right)$. 
$E_{\text {def }}=\left(E_{\text {drug in complex }}-E_{\text {drug }}\right)+\left(E_{\text {nanotube in complex }}-E_{\text {nanotube }}\right)$.

where $E_{\text {nanotube in complex, }} E_{\text {drug in complex }}$ are the energies of nanotube and drug with their geometries in the complex, respectively.

The thermodynamical parameters were also investigated such as changing in Gibbs free energy $(\Delta \mathrm{G})$, entropy $(\Delta \mathrm{S})$, and enthalpy $(\Delta \mathrm{H})$, to examine the structural stability using the following equations:[24]

$\Delta G=G_{\text {complex }}-G_{\text {nanotube }}-G_{\text {drug }}$

$\Delta H=H_{\text {complex }}-H_{\text {nanotube }}-H_{\text {drug }}$

$\Delta S=\frac{\Delta H-\Delta G}{T}$

where $\mathrm{G}_{\text {complex }}$ and $\mathrm{H}_{\text {complex }}$ are the Gibbs free energy and the enthalpy of drug adsorbed upon nanotubes, $\mathrm{G}_{\text {nano }}$ and $\mathrm{H}_{\text {nano }}$ are the Gibbs free energy and enthalpy of the nanotubes and $\mathrm{G}_{\mathrm{drug}}$ and $\mathrm{H}_{\text {drug }}$ are the Gibbs free energy and enthalpy of the drug respectively. (T) is the room temperature equal to (298.15K).

The nature of interactions between BMSF-BENZ and Si-CNT has been determined Quantum Theory of atoms in molecules (QTAIM) analysis of Bader's [25] which is implemented in MULTIWFN program [26]. The molecular orbital (MO) analysis has been evaluated by MULTIWFN 3.7 program using density of states (DOS). Recovery time has predicted to understand the desorption process of the drug molecule from Si-CNT surface when the adsorbents in the gas phase.

\section{Results and discussions}

\subsection{The optimized geometry of the adsorbents}

An adsorbent nanotube of zigzag Si-doped SWCNT $(n, 0)$ was considered for the BMSF-BENZ drug as an osteoporosis disease drug delivery vehicle. Initially, the nanotube and BMSF-BENZ molecule were optimized using DFT calculation in the gas media. The optimized geometries of adsorbent Si-CNT and drug molecules with their corresponding HOMO, LUMO, are shown in Figure 3. 


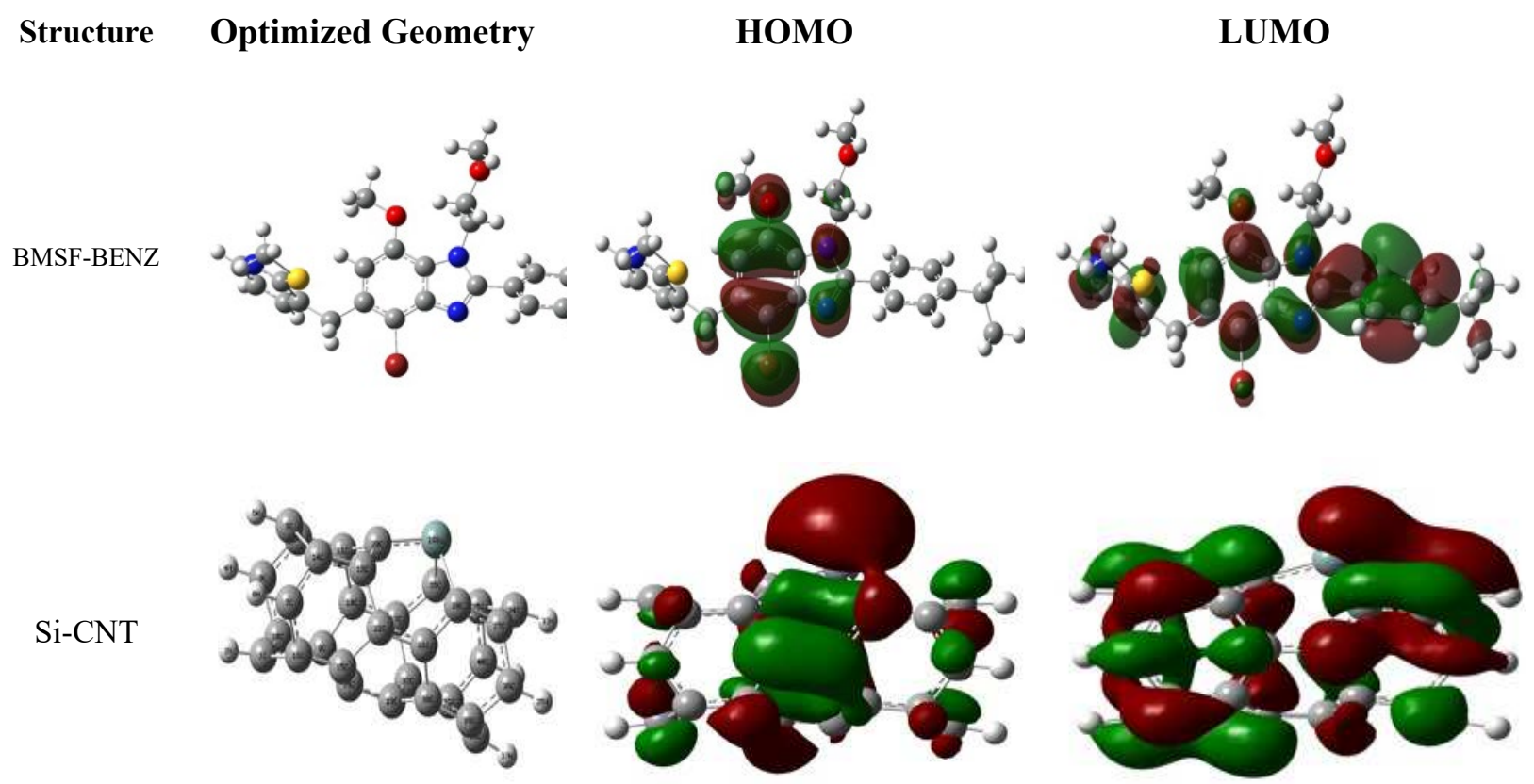

Fig. 3. Structures, HOMO, LUMO of the BMSF-BENZ drug, Si-CNT.

The vibrational modes for the new complexes and the original compounds were calculated to check the structural stability in the presence of IR. Where all compounds give vibrational modes with a positive frequency range of $(8.39,10.12,6.92,6.71,10.43,12.02,4.24) \mathrm{cm}^{-1}$ as a minimum value, and $(3241.55,3249.13,3229.78,3244.58,3241.58,3244.41,3236.36) \mathrm{cm}^{-1}$ as a maximum value for the active atom binding $\left(\mathrm{Br}, \mathrm{N}_{8}, \mathrm{~N}_{9}, \mathrm{~N}_{58}, \mathrm{O}_{35}, \mathrm{O}_{41}\right.$, and $\mathrm{S}$ ) with Si-CNT nanotube (Figure 2). Furthermore, the HOMO and LUMO energies were also calculated to find the energy gap of nanotubes.

HOMO levels are located on the center of the $\mathrm{C}-\mathrm{C}$ bonds throughout the nanotube, whereas LUMO levels were located all over the nanotube structure. The predicted energy gap of Si-CNT (1.66, $1.54,1.63,1.37,1.68,1.64,1.66) \mathrm{eV}$ for all locations, respectively.

\subsection{BMSF-BENZ adsorption on Si-CNT nanotube}

To detect suitable adsorbents for BMSF-BENZ, we attempted to verify various properties like geometric, electronic, adsorption properties, etc., of BMSF-BENZ/Si-CNT complexes. Initially, Si-CNT was exposed to the drug compound at different adsorption sites and the preferred adsorption sites for $\mathrm{Si}$ atoms were found as it approached $\left(\mathrm{Br}, \mathrm{N}_{8}, \mathrm{~N}_{9}, \mathrm{~N}_{58}, \mathrm{O}_{35}, \mathrm{O}_{41}, \mathrm{~S}\right)$ atoms of BMSF-Benz (Fig. 2).

In the case of the BMSF-BENZ adsorbed compound, the Si-CNT geometry remains unchanged, and the lengths of the $\mathrm{C}-\mathrm{C}$ bonds varied by about $0.03 \AA$ at the proximal adsorption site. It claims that there is an interaction between BMSF-BENZ and Si-CNT nanotubes, and this was confirmed by the adsorption energy and changes in the electronic properties analysis except when the nanotube approached the $\mathrm{N}_{9}$ nitrogen atom, we observed that the bond length was the same before and after adsorption which It means that there is no interaction between the nanotube and the drug compound at this point. 
The BMSF-BENZ drug molecule was adsorbed on the Si-CNT nanotube with an adsorption energy of about $(-5.15,-24.21,-8.22,-17.03,-13.16,-2.22$, and -12.70$) \mathrm{kcal} / \mathrm{mol}$ at a distance of at least about $(3.27,1.91,8.32,1.94,1.90,3.91$, and 2.37$) \AA$ in the B3LYP method as shown in Table 1. Due to the proximity of the bromine atom to the interaction region between the nanoparticle and the nitrogen atom $\left(\mathrm{N}_{9}\right)$, the bromine atom forced the silicon atom to move away from the nitrogen atom and prevented it from forming a bond between them, but instead, hydrogen bonds were formed between two hydrogen atoms in the nanoparticle with an atom Nitrogen in the drug compound and with spaces $(1.91,1.85)$ A respectively.

In order to analyze the adsorption and desorption process together, the charge $\mathrm{Q}(\mathrm{e})$ values for SiCNT by adsorption process and recovery time were obtained Under vacuum UV light conditions with a frequency of $\left(3 \times 10^{16}\right) \mathrm{sec}^{-1}$ at room temperature for the different complexes in the gas phase shown in Table 1.

Note that the length of the bonds between the silicon atom and the adjacent carbon atoms were $(1.80,1.89,1.89) \AA$, respectively, and the distance between the Si-CNT and every active atoms was (2.4) $\AA$.

Table 1. Adsorption energy (Eads) in (kcal/mol), the distance between BMSF-BENZ molecule, and adsorbents (d) in $(\AA)$, Bond length between active atoms of the nanotubes after adsorption of BMSF-BENZ drug for the different complex in gas phase, the DM denotes the dipole moment values of Si-CNT in (Debye) and recovery time $(\tau)$ in sec.

\begin{tabular}{|c|c|c|c|c|c|c|}
\hline Structure & d & $\mathbf{E}_{\text {ads }}$ & Bond location & $\begin{array}{c}\text { Bond length after } \\
\text { adsorption }\end{array}$ & DM & $\tau(\mathrm{sec})$ \\
\hline BMSF-BENZ & - & - & - & - & 1.82 & - \\
\hline \multirow[t]{2}{*}{ Si-CNT } & - & - & - & - & 0.64 & - \\
\hline & & & $\mathrm{Si}-\mathrm{C} 1$ & 1.79 & & \\
\hline \multirow[t]{3}{*}{$\mathrm{Br} / \mathrm{Si}-\mathrm{CNT}$} & 3.27 & -5.15 & $\mathrm{Si}-\mathrm{C} 2$ & 1.88 & 2.20 & $1.97 \times 10^{-13}$ \\
\hline & & & $\mathrm{Si}-\mathrm{C} 3$ & 1.88 & & \\
\hline & & & $\mathrm{Si}-\mathrm{C} 1$ & 1.79 & & \\
\hline \multirow[t]{3}{*}{$\mathrm{N}_{8} / \mathrm{Si}-\mathrm{CNT}$} & 1.91 & -24.21 & $\mathrm{Si}-\mathrm{C} 2$ & 1.85 & 5.92 & 17.9 \\
\hline & & & $\mathrm{Si}-\mathrm{C} 3$ & 1.86 & & \\
\hline & & & $\mathrm{Si}-\mathrm{C} 1$ & 1.80 & & \\
\hline \multirow[t]{3}{*}{$\mathrm{N}_{9} / \mathrm{Si}-\mathrm{CNT}$} & 8.32 & -8.22 & $\mathrm{Si}-\mathrm{C} 2$ & 1.89 & 1.70 & $3.49 \times 10^{-7}$ \\
\hline & & & $\mathrm{Si}-\mathrm{C} 3$ & 1.89 & & \\
\hline & & & $\mathrm{Si}-\mathrm{C} 1$ & 1.79 & & \\
\hline \multirow[t]{3}{*}{$\mathrm{N}_{58} / \mathrm{Si}-\mathrm{CNT}$} & 1.94 & -17.03 & $\mathrm{Si}-\mathrm{C} 2$ & 1.84 & 3.02 & $9.88 \times 10^{-5}$ \\
\hline & & & $\mathrm{Si}-\mathrm{C} 3$ & 1.89 & & \\
\hline & & & $\mathrm{Si}-\mathrm{C} 1$ & 1.78 & & \\
\hline \multirow[t]{2}{*}{$\mathrm{O}_{35} / \mathrm{Si}-\mathrm{CNT}$} & 1.90 & -13.16 & $\mathrm{Si}-\mathrm{C} 2$ & 1.84 & 1.63 & $1.45 \times 10^{-7}$ \\
\hline & & & $\mathrm{Si}-\mathrm{C} 3$ & 1.84 & & \\
\hline $\mathrm{O}_{41} / \mathrm{Si}-\mathrm{CNT}$ & 3.91 & -2.22 & $\mathrm{Si}-\mathrm{C} 1$ & 1.79 & 0.71 & $1.41 \times 10^{-15}$ \\
\hline
\end{tabular}




\begin{tabular}{|c|c|c|c|c|c|c|}
\hline & & & $\mathrm{Si}-\mathrm{C} 2$ & 1.88 & & \\
\hline & & & $\mathrm{Si}-\mathrm{C} 3$ & 1.88 & & \\
\hline & & & $\mathrm{Si}-\mathrm{C} 1$ & 1.78 & & \\
\hline $\mathrm{S} / \mathrm{Si}-\mathrm{CNT}$ & 2.37 & -12.70 & $\mathrm{Si}-\mathrm{C} 2$ & 1.84 & 1.94 & $6.66 \times 10^{-8}$ \\
\hline & & & $\mathrm{Si}-\mathrm{C} 3$ & 1.84 & & \\
\hline
\end{tabular}

Dipole moment refers to the polarity of the compound as it appears due to the asymmetric charge distribution as well as the difference in electronegativity between the resultant molecules or atoms, where the large dipole moment refers to the more polar structure which results in a more stable interaction of the structure [27].

The results of the dipole moment showed that the new compounds obtained from the adsorption of the drug compound on the surface of the nanotube had different values greater than the value that the drug had before adsorption. A more stable reaction occurred when the drug compound was adsorbed on the surface of the nanotube at $\mathrm{N}_{8}$ atom with the value of (5.92) Debye which was greater than the rest of the other active atoms of the drug compound.

\section{Quantum Theory of Atoms in Molecules (QTAIM) Analysis}

In order to understand the nature of interactions of BMSF-BENZ drug on Si-CNTs, Topology Analysis based on Bader's quantum theory of atoms in molecules (QTAIM) method has been employed with MULTIWFN program.

In QTAIM analysis, the nature of intermolecular interactions between drug and CNT is determined in terms of electron densities at bond critical points (BCPs).

The electron density of $\rho(r)$ and laplacian $\nabla^{2} \rho(r)$ characteristics are widely used to understand the bonding interactions nature. However, the other two parameters of total energy density of $\mathrm{H}(\mathrm{r})$ and the ratio of $|V(r)| / G(r)$ are more remarkable parameters used on bonding characteristics. The covalent bonding characteristics correspond to $\nabla^{2} \rho(r)<0, H(r)<0,|V(r)| / G(r)>2$. The strong hydrogen bonds as the intermediate type of interaction related to $\nabla^{2} \rho(r)>0, H(r)<$ $0,1<|V(r)| / G(r)<2$. The weak and medium-strength hydrogen bonding and Van der Waals interactions due to the $\nabla^{2} \rho(r)>0, H(r)>0,|V(r)| / G(r)<1$.

In this work, the QTAIM theory has been applied for the $\mathrm{N}_{8} / \mathrm{Si}-\mathrm{CNT}$ and $\mathrm{N}_{58} / \mathrm{Si}$-CNT complexes which are appeared having the first two higher adsorption energy values (in magnitude) given in Table 1. The calculated QTAIM parameters are displayed in Table 2 and the interactions between the drug and Si-CNT for the selected complexes are shown in Figure 4. 

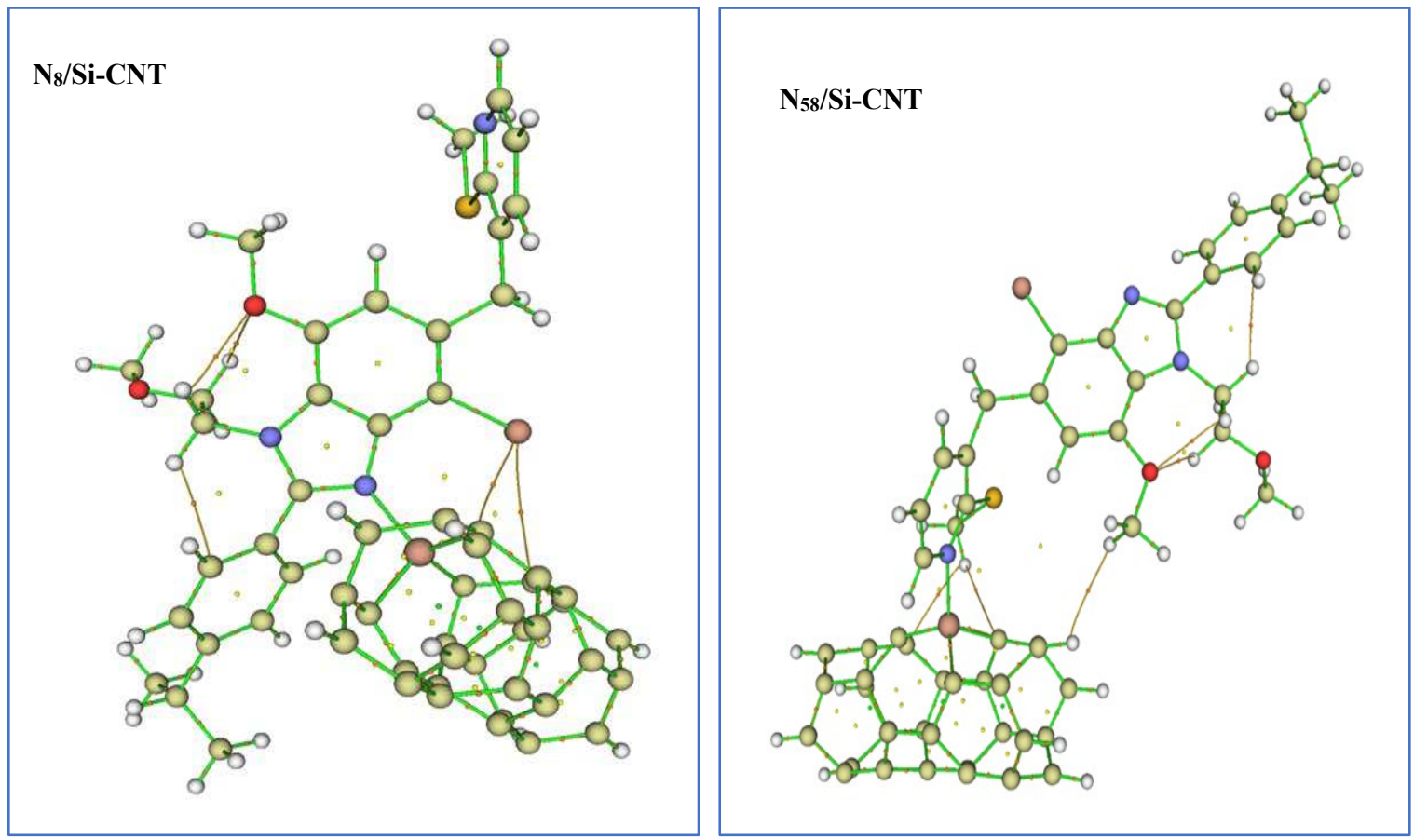

Fig. 4. The computed molecular topographical map of the complexes for BMSF-N $8 / \mathrm{Si}-\mathrm{CNT}$ and BMSF-N $58 / \mathrm{Si}_{-} \mathrm{CNT}$ The bond critical points are represented by orange spheres. The ring and cage critical points are displayed with yellow and green circles. The lines are bond paths.

Table 2 The QTAIM parameters of selected complexes at the BCPs. Electron density $(\rho(r))$, Laplacian of electron density $\left(\nabla^{2} \rho(r)\right)$, the kinetic electron density $(G(r))$, potential electron Density $(V(r))$, total electron energy density $(\mathrm{H}(\mathrm{r}))$, the ratio $\left|V_{B C P}\right| /_{B C P}$

\begin{tabular}{|c|c|c|c|c|c|c|c|}
\hline \multirow{2}{*}{ Structure } & $\begin{array}{c}\mathrm{BCP} \\
\text { Drug/Si-CNT }\end{array}$ & $\rho_{B C P}$ & $\nabla^{2} \rho_{B C P}$ & $\mathrm{GBCP}$ & $\mathrm{V}$ BCP & $\mathrm{HBCP}$ & $\left|V_{B C P}\right| / G_{B C P}$ \\
\hline \multirow{3}{*}{$\mathrm{N}_{8} / \mathrm{Si}-\mathrm{CNT}$} & $\mathrm{N}_{41}-\mathrm{Si}_{19}$ & 0.0826 & 0.2943 & 0.1021 & -0.1306 & -0.0285 & 1.2793 \\
\cline { 2 - 8 } & $\mathrm{Br}_{50}-\mathrm{C}_{26}$ & 0.0127 & 0.0371 & 0.0077 & -0.0061 & 0.0015 & 0.7941 \\
\cline { 2 - 8 } & $\mathrm{Br}_{50}-11$ & 0.0074 & 0.0210 & 0.0042 & -0.0032 & $0.983 \times 10^{-3}$ & 0.7694 \\
\hline \multirow{3}{*}{$\mathrm{N}_{58} / \mathrm{Si}-\mathrm{CNT}$} & $\mathrm{N}_{41}-\mathrm{Si}_{19}$ & 0.0796 & 0.2479 & 0.0914 & -0.1208 & -0.0294 & 1.3218 \\
\cline { 2 - 8 } & $\mathrm{H}_{57}-\mathrm{C}_{11}$ & 0.0072 & 0.0244 & 0.0048 & -0.0035 & 0.0013 & 0.7297 \\
\cline { 2 - 8 } & $\mathrm{H}_{57}-\mathrm{C}_{26}$ & 0.0093 & 0.0312 & 0.0062 & -0.0047 & 0.0015 & 0.7544 \\
\cline { 2 - 8 } & $\mathrm{H}_{74}-\mathrm{H}_{33}$ & 0.0039 & 0.0137 & 0.0025 & -0.0016 & $0.899 \times 10^{-3}$ & 0.6441 \\
\hline
\end{tabular}

It is clear in Table 2, the nature of interaction between $\mathrm{N}_{41}$ and $\mathrm{Si}_{19}$ atoms is semi-covalent character with the the ratio of $\left|V_{B C P}\right|_{G_{B C P}}>1$ which are for both studied complexes as 1.2793 and 1.3219. Those interactions of $\mathrm{N}_{41}$ can be classified as the intermediate type of interaction with $\left(\nabla^{2} \rho_{B C P}>0\right)$ with $\left(\mathrm{H}_{\mathrm{BCP}}<0\right)$ rule. All remaining interactions in Table 2 exhibit mainly van der Waals type weak and with medium-strength hydrogen bonding due to the ratio of $\left|V_{B C P}\right| /_{G_{B C P}}<1$.

The quantum descriptors denoted by Equations (1-4) are calculated for BMSF-BENZ /Si-CNT complex structures and given in Table 3. In the BMSF-BENZ/Si-CNT structure, the electronic parameters such as Еномо, Elumo, Eg, and Fermi energies have a noticeable change. The values 
of Eномо and ELumo of Si-CNT nanotubes before the adsorption of molecules are (-4.91 and -3.30) $\mathrm{eV}$, and after adsorption of BMSF-BENZ drug are mentioned in Table 3. The sensors are related to the variation of their electrical conductance after drug adsorption due to the electron exchange between the drug and sensor. On this line, the CNT sensitivity to the drug is based on the changing of HOMO and LUMO energies with Eg.

In order to understand the sensing mechanism of the Si-CNT to drug, the percentage variation of $\% \Delta E_{g}$ energy gap during the adsorption process is taken into account by the following equation:

$\% \Delta E_{g}=100 x\left(E_{g 2}-E_{g 1}\right) / E_{g 1}$

where $E_{g 1}$ and $E_{g 2}$ are the $E_{g}$ values of CNT and complex structure, respectively. The percentage change values, of $\% \Delta E_{g}$ for each structure are given in Table 3. The percent change in the work function as $\% \Delta \Phi$ can be derived by logic in band gap energies given in Eq.(9).

The corresponding frontier molecular orbital map is shown in Figure 5, and the Frontier molecular orbital (HOMO and LUMO) of all investigated complexes is shown in Figure 6. Thus, the BMSFBENZ drug molecule was significantly affecting the HOMO energy level and LUMO energy level as shown in Table 3.

Table 3. Calculated $\mathrm{E}_{\text {Hомо }}$, $\mathrm{E}_{\mathrm{LuMO}}$ energies, HOMO-LUMO gap $\left(\mathrm{E}_{\mathrm{g}}\right)$, Fermi level energy $\left(\mathrm{E}_{\mathrm{f}}\right)$, and work function $(\Phi)$, the percentage variation of $\mathrm{E}_{\mathrm{g}}$ and $\Phi$ respect to bare Si-CNT for the studied complexes.

\begin{tabular}{cccccccc}
\hline Structure & $\begin{array}{c}\mathbf{E}_{\text {Hомо }} \\
(\mathbf{e V})\end{array}$ & $\begin{array}{c}\mathbf{E}_{\mathbf{L u m o}} \\
(\mathbf{e V})\end{array}$ & $\mathbf{E}_{\mathbf{g}}$ & $\mathbf{\%} \mathbf{\Delta E g}$ & $\begin{array}{c}\mathbf{E}_{\mathbf{f}} \\
\mathbf{( e V})\end{array}$ & $\mathbf{\Phi}$ & $\mathbf{\%} \boldsymbol{\Delta} \boldsymbol{\Phi}$ \\
\hline BMSF-BENZ & -5.40 & -0.88 & 4.52 & - & -3.14 & 3.14 & - \\
$\mathrm{Si}-\mathrm{CNT}$ & -4.91 & -3.30 & 1.61 & - & -4.10 & 4.10 & - \\
$\mathrm{Br} / \mathrm{Si}-\mathrm{CNT}$ & -4.62 & -2.96 & 1.66 & 3.10 & -3.79 & 3.79 & -7.56 \\
$\mathrm{~N}_{8} / \mathrm{Si}-\mathrm{CNT}$ & -3.43 & -1.88 & 1.54 & -4.35 & -2.66 & 2.66 & -35.12 \\
$\mathrm{~N}_{9} / \mathrm{Si}-\mathrm{CNT}$ & -4.57 & -2.93 & 1.63 & 1.24 & -3.75 & 3.75 & -8.53 \\
$\mathrm{~N}_{58} / \mathrm{Si}-\mathrm{CNT}$ & -3.93 & -2.56 & 1.37 & -14.90 & -3.25 & 3.25 & -20.73 \\
$\mathrm{O}_{35} / \mathrm{Si}-\mathrm{CNT}$ & -4.18 & -2.50 & 1.68 & 4.35 & -3.34 & 3.34 & -18.54 \\
$\mathrm{O}_{41} / \mathrm{Si}-\mathrm{CNT}$ & -4.95 & -3.30 & 1.64 & 1.86 & -4.12 & 4.12 & 0.49 \\
$\mathrm{~S} / \mathrm{Si}-\mathrm{CNT}$ & -4.08 & -2.42 & 1.66 & 3.10 & -3.25 & 3.25 & -20.73 \\
\hline
\end{tabular}




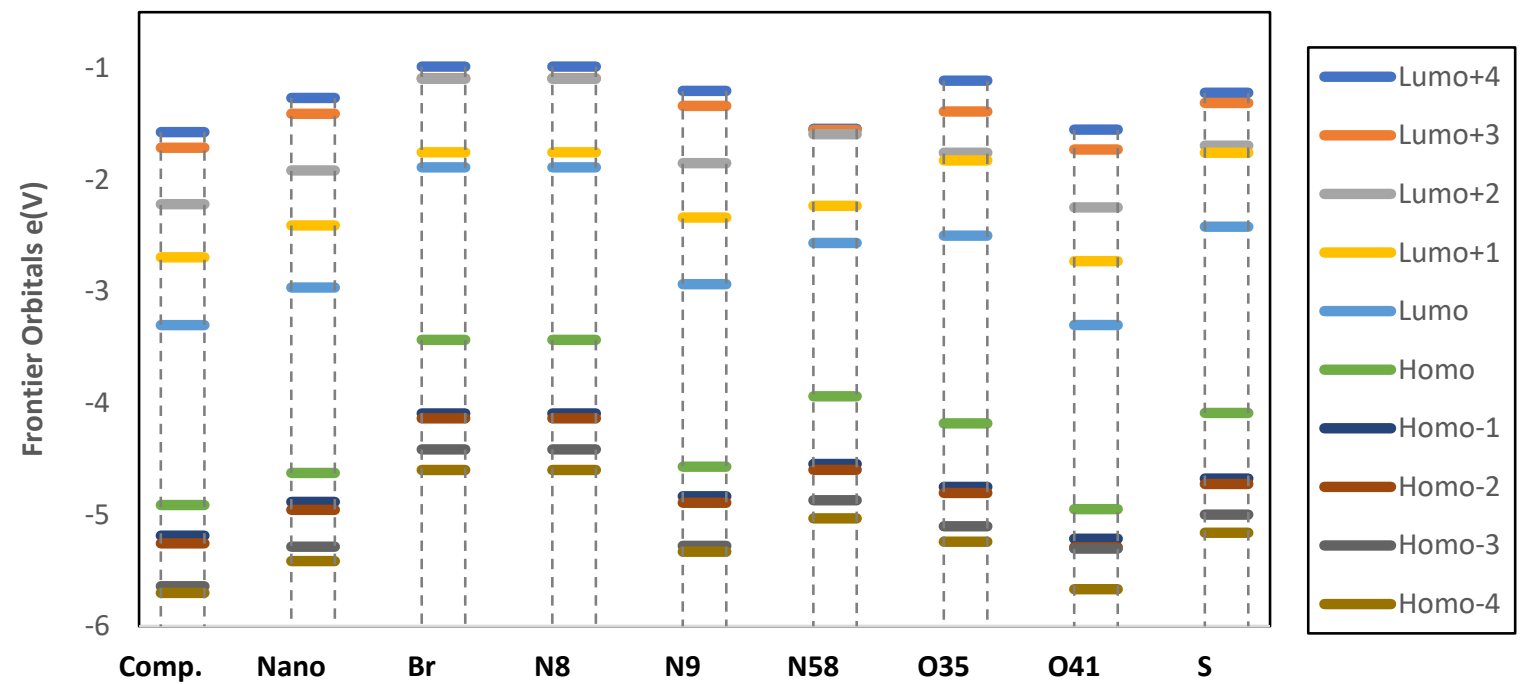

Figure 5. Energy gap between HOMO and LUMO for BMSF-BENZ drug, Si-CNT nanotube, with all investigated locations regarding to the position of the nanotube on the drug.

As reported energies of EHomo, Elumo and $\mathrm{E}_{\mathrm{g}}$ in Table 3, some electronic properties of Si-CNT are affected weakly by the adsorption of the BMSF-BENZ drug. The decreasing order of percentage change values are obtained for the interactions of $\mathrm{N}_{8}$, and $\mathrm{N}_{58}$ atoms of the BMSFBENZ drug with Si-CNT as $-4.35 \%,-14.90 \%$, but for other atoms of $\left(\mathrm{Br}, \mathrm{N}_{9}, \mathrm{O}_{35}, \mathrm{O}_{41}\right.$, and $\left.\mathrm{S}\right)$ are about $(3.10 \%, 1.24 \%, 4.35 \%, 1.86 \%, 3.10 \%)$ by increasing.

It is known that the lower Eg values indicate higher electrical conductivity, reactivity, and sensitivity. Therefore, decreasing the Eg through adsorption of the BMSF-BENZ drug molecule indicates that the Si-CNT can detect the drug. Thus, among all studied geometries of complex structures, the highest variation value of $\% \mathrm{Eg}$ has been obtained by the $\mathrm{N}_{58}$ atom of the BMSFBENZ interacts with Si-CNT nanotube.

According to the values of percentage variation in the work function of $\% \Phi$, the structure corresponding to $\mathrm{O}_{41} / \mathrm{Si}-\mathrm{CNT}$ has the highest value of $\% 0.49$ by increasing the conduction electrons.

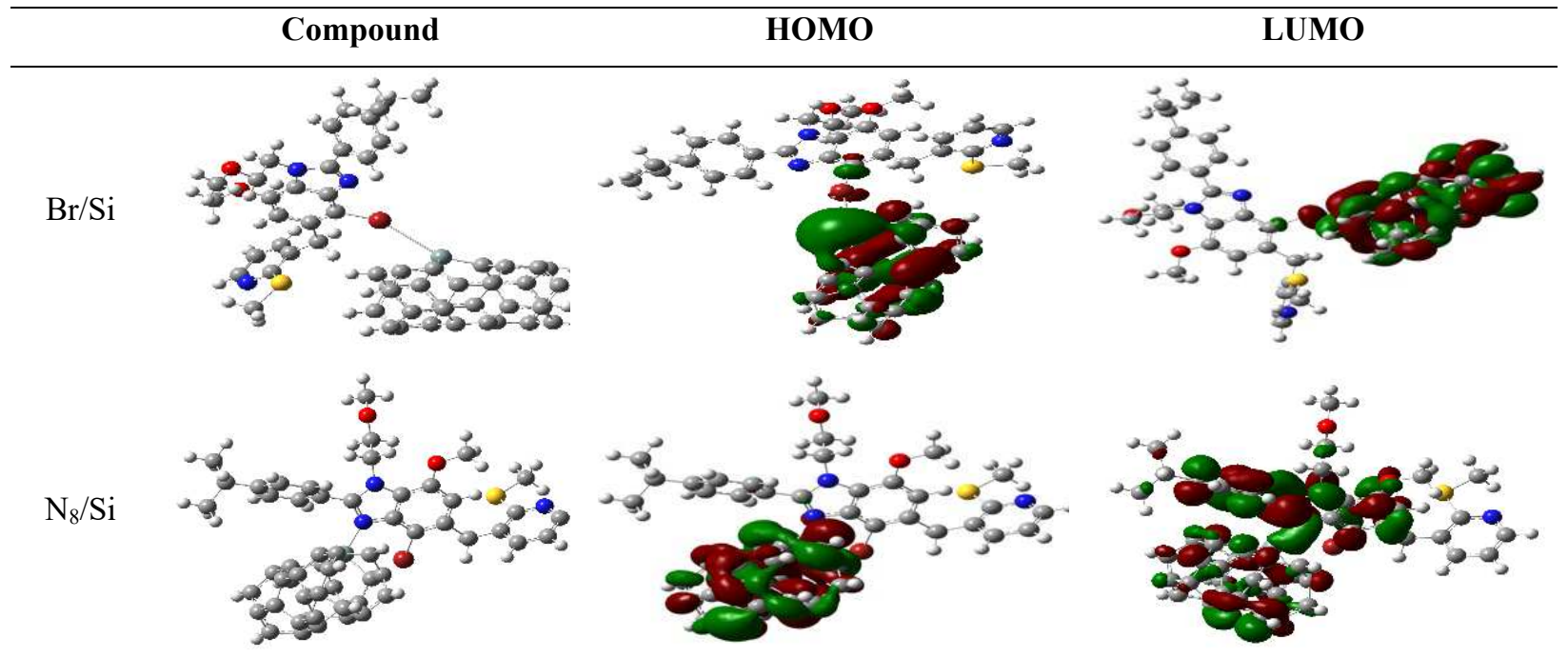




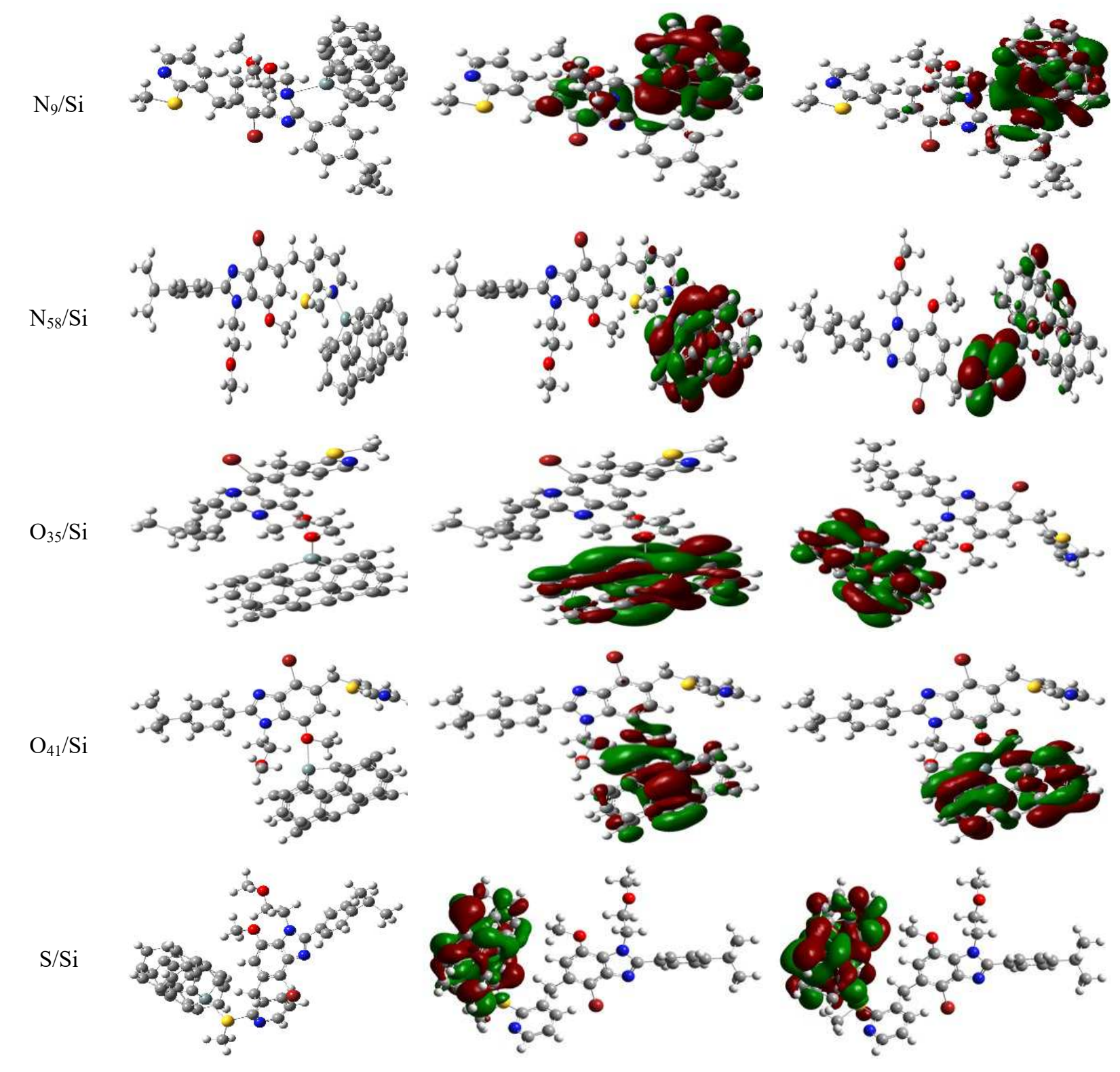

Figure 6. The Frontier molecular orbital (HOMO and LUMO) of all investigated new complexes; the considered iso value is 0.02 electron/bohr3.

The recovery time (adsorption time) is one of the important parameters used for both gas sensors and drug delivery systems, which predicts the amount of time required for drug adsorption from the adsorbent, as it is highly related to the adsorption energy, and it is known that a high adsorption reaction needs a high adsorption time and vice versa.

The recovery time is calculated by the equation: [28]

$\tau=\frac{1}{v} \operatorname{Exp}\left(\frac{-E_{a d s}}{k T}\right)$

Where $\mathrm{T}, \mathrm{k}$, and $v$ are the temperature, Boltzmann's constant and the attempted frequency, respectively. $\left(\mathrm{k} \sim 2 \times 10^{-3} \mathrm{kcal} / \mathrm{mol} \mathrm{K}\right)$ 
As the BMSF-BENZ molecule seems to be adsorbed on the Si-CNT nanotube with maximum adsorption energy, a different recovery time (Table1) was obtained in vacuum UV- light conditions with frequencies of $3 \times 10^{16} \mathrm{sec}^{-1}$ at room temperature.

When the adsorption energy is more than $1 \mathrm{eV}(23.061 \mathrm{kcal} / \mathrm{mol})$ (in magnitude), a strong chemical interaction between adsorbate and adsorbent is considered to occur, and the adsorption process is then leveled as chemisorption. Therefore, the more negative value of the adsorption energy, the stronger the connection of the system and represents a higher static system, so the adsorption process between drug molecules and the adsorbent is supposed to give negative values of adsorption energy.

It is also known that in drug delivery systems, the adsorbent must have a strong interaction with the drug, and for drug sensors, there must be less energy expenditure [29].

By combining the corresponding recovery time values of those complexes in Table1 with the percentage variation of work function given in Table 3, it has been evaluated that those complexes cannot be used as amperometric drug sensor applications of BMSF-BENZ drug molecule on SiCNT nanotube.

Those values indicate that the adsorption process of $\mathrm{N}_{8} / \mathrm{Si}-\mathrm{CNT}$ and $\mathrm{N}_{58} / \mathrm{Si}-\mathrm{CNT}$ complexes are in physisorption nature with the desorption time values of $17.9 \mathrm{sec}$, and $9.88 \times 10^{-5} \mathrm{sec}$, respectively. Among them, the complex of $\mathrm{N}_{8} / \mathrm{Si}-\mathrm{CNT}$ can be extended as a drug delivery system with a reasonable recovery time.

In order to prove the importance of (DOS) calculations in the field of quantum chemistry, researchers interested in this topic have found gradual relationships between the absorption energies between different adsorbents on the surfaces of nanoparticles and the scaling relationships between adsorption energies and interaction transfer barriers that lead to the so-called volcanic activity cutoff. These schemes indicate that the optimal catalyst must have a strong bonding with the molecules and atoms participating in the interaction, which enables these molecules to bond well on the surface of the nanoparticles, as it does not reduce or impede the absorption of products.[30]

The lower Eg values indicate higher electrical conductivity, reactivity, and sensitivity. Therefore, decreased the Eg through adsorption of BMSF-BENZ drug indicates the CNT can detect the drug.

The density of states (DOS) diagram of the complex structure of the N58 atom of the BMSF-BENZ interacting with Si-CNT was selected to plot in Figure 7 because of the significant $\% \Delta \mathrm{Eg}$ values are given in Table 3, each was also calculated in order to better understand the stability of the system. The change in Eg by DOS analysis can be confirmed as shown in Figure7 by the MULTIWFN program. 


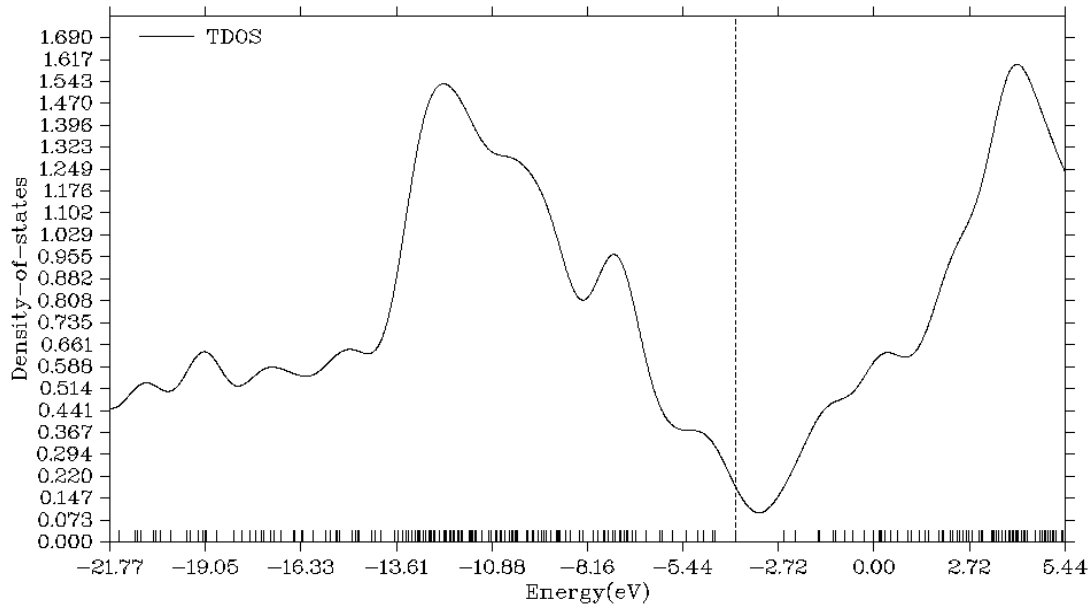

Figure 7. TDOS plot for complex structure of N58-BMSF-BENZ /Si-CNT. The dashed line shows the HOMO energy level.

It is clear in Figure 7 that the bandgap of the complex is getting narrow concerning the Eg of Si$\mathrm{CNT}$. The recovery time is related to the adsorption energy, as a high adsorption reaction needs a high adsorption time and vice versa.

It is known that positive values of $\Delta \mathrm{H}$ and $\mathrm{G}$ indicate that the reaction process is endothermic rather than spontaneous. In contrast, negative values of $\Delta \mathrm{H}$ and $\mathrm{G}$ indicate that the reaction is an exothermic and spontaneous process [31] (see Table 4).

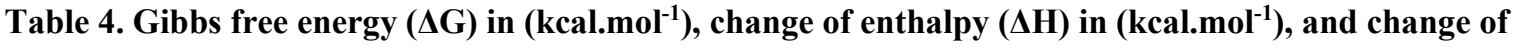
entropy $(\Delta S)$ in $(\mathrm{kcal} / \mathrm{mol} . \mathrm{K})$, minimum and maximum frequency in $\mathrm{cm}^{-1}$ for the different complexes.

\begin{tabular}{ccccccc}
\hline & Structure & $\Delta \mathbf{G}$ & $\Delta \mathbf{H}$ & $\Delta \mathbf{S}$ & $\mathbf{v}_{\min }$ & $\mathbf{v}_{\max }$ \\
\hline 1 & $\mathrm{Br} / \mathrm{Si}-\mathrm{CNT}$ & 7.04 & -4.87 & -0.03 & 8.39 & 3241.55 \\
2 & $\mathrm{~N}_{8} / \mathrm{Si}-\mathrm{CNT}$ & -23.07 & -36.45 & -0.04 & 10.12 & 3249.13 \\
3 & $\mathrm{~N}_{9} / \mathrm{Si}-\mathrm{CNT}$ & 3.25 & -8.32 & -0.03 & 6.92 & 3229.78 \\
4 & $\mathrm{~N}_{58} / \mathrm{Si}-\mathrm{CNT}$ & -18.72 & -29.68 & -0.03 & 6.71 & 3244.58 \\
5 & $\mathrm{O}_{35} / \mathrm{Si}-\mathrm{CNT}$ & -11.03 & -24.55 & -0.04 & 10.43 & 3241.58 \\
6 & $\mathrm{O}_{41} / \mathrm{Si}-\mathrm{CNT}$ & -1.88 & -8.53 & -0.02 & 12.02 & 3244.41 \\
7 & $\mathrm{~S} / \mathrm{Si}-\mathrm{CNT}$ & -1.14 & -15.82 & -0.04 & 4.24 & 3236.36 \\
\hline
\end{tabular}

The obtained data for $\Delta \mathrm{H}$ and $\Delta \mathrm{G}$ were negative values in all the examined complexes except upon adsorption of the drug at the bromine atom, that is, these complexes are dynamically stable, and the most negative value of $\Delta \mathrm{S}$ means the most ordered compound. Therefore, thermodynamic parameters predict that the investigated complexes are more suitable and thermodynamically stable for BMSF-BENZ drug delivery.

\section{Conclusions}


In order to obtain a suitable drug delivery method for BMSF-BENZ, we examined the adsorption behavior of BMSF-BENZ on Si-CNT surface using DFT calculations. It was observed that the BMSF-BENZ molecule was adsorbed onto the nanostructures with different adsorption energy depending on the nanotube location of the active drug atoms.

The HOMO energy (Еномо), LUMO energy (ELUMO), HOMO-LUMO energy gap, and Fermi level energies were changed after the adsorption of the BMSF-BENZ drug on the surface of Si-CNT. The BMSF-BENZ drug was adsorbed on the Si-CNT nanotube with an adsorption energy of $(-5.15,-24.21,-8.22,-17.03,-13.16,-2.22$, and -12.70$) \mathrm{kcal} / \mathrm{mol}$ in the gas phase at the B3LYP method, which is more favorable for the drug delivery system and the work function type sensor applications.

Moreover, Gibbs free energy shows that the BMSF-BENZ/Si-CNT formation exhibits spontaneous and favorable adsorption energy. Therefore, we can suggest that the Si-CNT nanotube will be a promising drug delivery medium for BMSF-BENZ drug molecules.

Based on the calculated results, it can be considered that the best site for adsorption of BMSFBENZ on the Si-CNT surface is when the nanotube approaches the nitrogen atom $\left(\mathrm{N}_{8}\right)$ where the best energy and appropriate recovery time were obtained.

\section{Declarations:}

\begin{tabular}{|c|c|}
\hline Funding: & (Not applicable' for that section) \\
\hline Conflicts of interest/Competing interests: & (Not applicable' for that section) \\
\hline Availability of data and material: & $\begin{array}{l}\text { (All the required data and calculations } \\
\text { included in this research are original and not } \\
\text { extracted from previous research, except } \\
\text { for some paragraphs in the Introduction } \\
\text { section taken as citations.) }\end{array}$ \\
\hline Code availability: & (Not applicable' for that section) \\
\hline Authors' contributions: & $\begin{array}{l}\text { (All the authors participating in this research } \\
\text { cooperated in it in equal proportions, as the } \\
\text { work was distributed according to its } \\
\text { specialization) }\end{array}$ \\
\hline
\end{tabular}

\section{References}

1. Cooper, C., Campion, G., \& Melton, L. J. Hip fractures in the elderly: A world-wide projection. Osteoporosis International, (1992), 2(6), 285-289. https://doi.org/10.1007/BF01623184.

2. Tuck, S. P., \& Francis, R. M. Osteoporosis. Postgraduate Medical Journal, (2002), 78(923), 526-532. https://doi.org/10.1136/pmj.78.923.526. 
3. Eastell, R., Boyle, I. T., Compston, J., Cooper, C., Fogelman, I., Francis, R. M., ... Stevenson, J. C. Management of male osteoporosis: Report of the UK consensus group. QJM - Monthly Journal of the Association of Physicians, (1998), 91(2), 71-92. https://doi.org/10.1093/qjmed/91.2.71.

4. Gerspacher, M., Altmann, E., Beerli, R., Buhl, T., Endres, R., Gamse, R., Widler, L. Pentasubstituted benzimidazoles as potent antagonists of the calcium-sensing receptor (CaSRantagonists). Bioorganic and Medicinal Chemistry Letters, 2010, 5161-5164. https://doi.org/10.1016/j.bmcl.2010.07.016.

5. Gu, M., Zhang, Q., \& Lamon, S. Nanomaterials for optical data storage. Nature Reviews Materials, (2016), 1(12), 1-14. https://doi.org/10.1038/natrevmats.2016.70.

6. Varghese, S. S., Lonkar, S., Singh, K. K., Swaminathan, S., \& Abdala, A. Recent advances in graphene based gas sensors. Sensors and Actuators, B: Chemical, (2015), 218, 160-183. https://doi.org/10.1016/j.snb.2015.04.062.

7. Rad, A. S., \& Ayub, K. Ni adsorption on A112P12 nano-cage: A DFT study. Journal of Alloys and Compounds, (2016), 317-324. https://doi.org/10.1016/j.jallcom.2016.03.175.

8. Pannopard, P., Khongpracha, P., Probst, M., \& Limtrakul, J. Gas sensing properties of platinum derivatives of single-walled carbon nanotubes: A DFT analysis. Journal of Molecular Graphics and Modelling, (2009), 28(1), 62-69. https://doi.org/10.1016/j.jmgm.2009.04.005.

9. Conti, M., Tazzari, V., Baccini, C., Pertici, G., Serino, L. P., \& De Giorgi, U. (2006). Anticancer drug delivery with nanoparticles. In vivo (Athens, Greece), 20(6A), 697-701.

10. Singh, R., \& Lillard, J. W. (2009). Nanoparticle-based targeted drug delivery. Experimental and Molecular Pathology, 86(3), 215-223. https://doi.org/10.1016/j.yexmp.2008.12.004.

11. Bakry, R., Vallant, R. M., Najam-ul-Haq, M., Rainer, M., Szabo, Z., Huck, C. W., \& Bonn, G. K. (2007). Medicinal applications of fullerenes. International Journal of Nanomedicine, 2(4), 639-649.

12. Zhang, T., Mubeen, S., Myung, N. V., \& Deshusses, M. A. (2008). Recent progress in carbon nanotube-based gas sensors. Nanotechnology, 19(33). https://doi.org/10.1088/0957-4484/19/33/332001.

13. Haidary, S. M., Córcoles, E. P., \& Ali, N. K. (2012). Nanoporous silicon as drug delivery systems for cancer therapies. Journal of Nanomaterials, 2012. https://doi.org/10.1155/2012/830503.

14. Gowri Sankar, P. A., \& Udhayakumar, K. (2013). Electronic properties of boron and silicon doped $(10,0)$ zigzag single-walled carbon nanotube upon gas molecular adsorption: A DFT comparative study. Journal of Nanomaterials, 2013(2). https://doi.org/10.1155/2013/293936.

15. Martínez-Vázquez, F. J., Cabañas, M. V., Paris, J. L., Lozano, D., \& Vallet-Regí, M. (2015). Fabrication of novel Si-doped hydroxyapatite/gelatine scaffolds by rapid prototyping for drug delivery and bone regeneration. Acta Biomaterialia, 15(2015), 200209. https://doi.org/10.1016/j.actbio.2014.12.021.

16. Bagheri, R., Babazadeh, M., Vessally, E., Es'haghi, M., \& Bekhradnia, A. (2018). Si-doped phagraphene as a drug carrier for adrucil anti-cancer drug: DFT studies. Inorganic Chemistry Communications, 90, 8-14. https://doi.org/10.1016/j.inoche.2018.01.020. 
17. Bilge, M. (2017). Adsorption Mechanism and Structural Investigation of Doped C60 FullerenesWith Pentylamine. ANADOLU UNIVERSITY JOURNAL OF SCIENCE AND TECHNOLOGY A - Applied Sciences and Engineering, 1-1. https://doi.org/10.18038/aubtda.281646

18. D.J.F. M. J. Frisch, G. W. Trucks, H. B. Schlegel, G. E. Scuseria, M. A. Robb, J. R. Cheeseman, G. Scalmani, V. Barone, B. Mennucci, G. A. Petersson, H. Nakatsuji, M. Caricato, X. Li, H. P. Hratchian, A. F. Izmaylov, J. Bloino, G. Zheng, J. L. Sonnenberg, M. Had, M.J. Frisch, G.W. Trucks, H.B. Schlegel, G.E. Scuseria, M.A. Robb, J.R. Cheeseman, G. Scalmani, V. Barone, B. Mennucci, G.A. Petersson, H. Nakatsuji, M. Caricato, X. Li, H.P. Hratchian, A.F. Izmaylov, J. Bloino, G. Zheng, J. L. Sonnenberg, M. Hada, M. Ehara, K. Toyota, R. Fukuda, J. Hasegawa, M. Ishida, T. Nakajima, Y. Honda, O. Kitao, H. Nakai, T. Vreven, J.A. Montgomery Jr., J.E. Peralta, F. Ogliaro, M. Bearpark, J.J. Heyd, E. Brothers, K.N. Kudin, V.N. Staroverov, R. Kobayashi, J. Normand, K. Raghavachari, A. Rendell, J.C. Burant, S. S. Iyengar, J. Tomasi, M. Cossi, N. Rega, J.M. Millam, M. Klene, J.E. Knox, J.B. Cross, V. Bakken, C. Adamo, J. Jaramillo, R. Gomperts, R.E. Stratmann, O. Yazyev, A.J. Austin, R. Cammi, C. Pomelli, J.W. Ochterski, R.L. Martin, K. Morokuma, V.G. Zakrzewski, G.A. Voth, P. Salvador, J.J. Dannenberg, S. Dapprich, A.D. Daniels, "O. Farkas, J.B. Foresman, J. V Ortiz, J. Cioslowski, D.J. Fox, Gaussian 09, Revision D.01, Gaussian Inc., Wallingford. (2013). DOI: https://10.1017/CBO9781107415324.004.

19. Ahmed Hassen Shntaif, Rashi, Z.M., Al-Sawaff, Z.H. et al. Quantum Chemical Calculations on Two Compounds of Proquazone and Proquazone Type Calcites as a Calcium Sensing Receptor (CaSR) Inhibitory Profiles. Russ J Bioorg Chem 47, 777-783 (2021). https://doi.org/10.1134/S106816202103016X.

20. Al-Otaibi, J. S., Mary, Y. S., Mary, Y. S., \& Serdaroglu, G. (2021). Adsorption of adipic acid in A1/B-N/P nanocages: DFT investigations. Journal of Molecular Modeling, 27(4), 1-7. https://doi.org/10.1007/s00894-021-04742-z.

21. Bashiri, S., Vessally, E., Bekhradnia, A., Hosseinian, A., \& Edjlali, L. (2017). Utility of extrinsic [60] fullerenes as work function type sensors for amphetamine drug detection: DFT studies. Vacuum, 136, 156-162. https://doi.org/10.1016/j.vacuum.2016.12.003.

22. Hossain, M. A., Hossain, M. R., Hossain, M. K., Khandaker, J. I., Ahmed, F., Ferdous, T., \& Hossain, M. A. (2020). An ab initio study of the B35 boron nanocluster for application as atmospheric gas (NO,NO2,N2O,NH3) sensor. Chemical Physics Letters, 754(2), 137701. https://doi.org/10.1016/j.cplett.2020.137701.

23. Li, J., Lu, Y., Ye, Q., Cinke, M., Han, J., \& Meyyappan, M. (2003). Carbon nanotube sensors for gas and organic vapor detection. Nano Letters, 3(7), 929-933. https://doi.org/10.1021/n1034220x.

24. Qiao, Z., Wang, Z., Zhang, C., Yuan, S., Zhu, Y., \& Wang, J. (2012). PVAm-PIP/PS composite membrane with high performance for $\mathrm{CO}_{2} / \mathrm{N}_{2}$ separation. AIChE Journal, 59(4), 215-228. https://doi.org/10.1002/aic.

25. Matta, C. F., \& Bader, R. F. W. (2003). Atoms-in-molecules study of the genetically encoded amino acids. III. Bond and atomic properties and their correlations with experiment including mutation-induced changes in protein stability and genetic coding. Proteins: Structure, Function and Genetics, 52(3), 360-399. https://doi.org/10.1002/prot.10414. 
26. Lu, T., \& Chen, F. (2012). Multiwfn: A multifunctional wavefunction analyzer. Journal of Computational Chemistry, 33(5), 580-592. https://doi.org/10.1002/jcc.22885.

27. Shamim, S. U. D., Hussain, T., Hossian, M. R., Hossain, M. K., Ahmed, F., Ferdous, T., \& Hossain, M. A. (2020). A DFT study on the geometrical structures, electronic, and spectroscopic properties of inverse sandwich monocyclic boron nanoclusters ConBm ( $\mathrm{n}=$ 1.2; $\mathrm{m}=6-8)$. Journal of Molecular Modeling, 26(6). https://doi.org/10.1007/s00894-02004419-Z.

28. Rad, A. S., Valipour, P., Gholizade, A., \& Mousavinezhad, S. E. (2015). Interaction of $\mathrm{SO} 2$ and $\mathrm{SO} 3$ on terthiophene (as a model of polythiophene gas sensor): DFT calculations. Chemical Physics Letters, 639, 29-35. https://doi.org/10.1016/j.cplett.2015.08.062.

29. Al-Sawaff, Z., Dalgic, S., \& Kandemirli, F. (2021). Theoretical study of the adsorption of BMSF-BENZ drug for osteoporosis disease treatment on Al-doped carbon nanotubes (AlCNT) as a drug delivery vehicle. European Journal of Chemistry, 12(3), 314-322. doi:10.5155/eurjchem.12.3.314-322.2143.

30. Aarons, J., Verga, L. G., Hine, N. D. M., \& Skylaris, C. K. (2019). Atom-projected and angular momentum resolved density of states in the ONETEP code. Electronic Structure, l(3). https://doi.org/10.1088/2516-1075/ab34f5.

31. Shahabi, M., \& Raissi, H. (2018). Screening of the structural, topological, and electronic properties of the functionalized Graphene nanosheets as potential Tegafur anticancer drug carriers using DFT method. Journal of Biomolecular Structure and Dynamics, 36(10), 2517-2529. https://doi.org/10.1080/07391102.2017.1360209. 